\title{
ORGANIZAÇÃO RETÓRICA DA APRESENTAÇÃO DO PROBLEMA DE ESTUDO DE PROJETOS DE PESQUISA DE HISTÓRIA ${ }^{1}$
}

\author{
RHETORIC ORGANIZATION OF THE PRESENTATION OF THE STUDY \\ PROBLEM OF HISTORY RESEARCH PROJECTS
}

\author{
Recebido: 11/05/2020 | Aprovado: 29/06/2020 | Publicado: 10/07/2020 \\ DOI: https://doi.org/10.18817/rlj.v4i1.2218
}

Jancen Sérgio Lima de Oliveira ${ }^{2}$

Orcid ID: https://orcid.org/0000-0001-5303-7788

Francisco Alves Filho
Orcid ID: https://orcid.org/0000-0002-2284-4197

\begin{abstract}
Resumo: Nosso objetivo com esta pesquisa é analisar a seção Apresentação do problema de estudo de projetos de pesquisa de História, descrevendo os passos retóricos recorrentes usados pelos produtores do gênero. Nosso corpus é composto por quinze projetos de pesquisa submetidos e aprovados na seleção para o ingresso no curso de mestrado em História do Brasil da Universidade Federal do Piauí, nos anos de 2014 e 2015. Baseamo-nos, principalmente, na abordagem sociorretórica de gêneros de Swales (1990), Miller (2009) e Bazerman (2015). A análise ocorreu da seguinte forma: inicialmente, fizemos a leitura dos projetos de pesquisa na íntegra, para que houvesse uma compreensão geral das ideias dos candidatos, posteriormente, partimos para a leitura mais detalhada da seção de "apresentação do problema de estudo" mesmo que esta estivesse denominada de formas diferentes, por fim, descrevemos os passos retóricos utilizados de forma mais recorrente pelos candidatos ao mestrado acadêmico em História. Os resultados das análises nos mostraram que os escritores costumam apresentar, na seção de apresentação, além do tema da pesquisa, os objetivos do estudo, suas indagações e relatos históricos. Esta pesquisa pretende contribuir com a comunidade acadêmica, pois poderá mostrar, aos futuros candidatos ao mestrado em História, quais os passos retóricos mais usados na composição do projeto de pesquisa, especificamente, na seção de "apresentação do problema de pesquisa".
\end{abstract}

Palavras-chave: Projeto de pesquisa. Gêneros acadêmicos. Organização retórica.

Abstract: Our objective with this research is to analyze the Research Problem Presentation section of History research projects, describing the recurring rhetorical steps used by the genre producers. Our corpus is composed of fifteen research projects submitted and approved in the selection for admission to the Master's degree in History of Brazil at the Federal University of Piauí, in 2014, 2015 and 2016. We mainly rely on the socio-rhetorical approach of genres of Swales (1990), Miller (2009) and Bazerman (2015). The analysis proceeded as follows: initially, we read the research projects in their entirety, so that there was a general understanding of the candidates' ideas, then we proceeded to a more detailed reading of the "study problem presentation" section even though If it were termed in different ways, we finally describe the rhetorical steps most commonly used by candidates for the Master's degree in

\footnotetext{
${ }^{1}$ Esse artigo é fruto de pesquisa realizada no Programa de Iniciação Científica Voluntária - ICV/UFPI (LIMA DE OLIVEIRA, 2019).

2 Mestrando em Letras, área de concentração Estudos da Linguagem, pelo Programa de PósGraduação em Letras da Universidade Federal do Piauí (PPGEL/UFPI). Graduado em Letras - Língua Portuguesa, pela Universidade Federal do Piauí - UFPI. Foi bolsista de Iniciação Científica Voluntária (ICV/UFPI) e Residência Pedagógica (RP/UFPI). É membro do Núcleo de Pesquisa em Texto, Gênero e Discurso - Cataphora (UFPI). E-mail: jancensergio@hotmail.com

3 Professor doutor, associado da Universidade Federal do Piauí - UFPI. Coordena o Núcleo de Pesquisa CATAPHORA, através do qual coordena uma pesquisa, com financiamento do CNPQ, sobre letramento acadêmico com foco na escrita de projetos de pesquisa. É membro do comitê de Assessoramento Técnico-Científico do PIBIC/UFPI e do comitê de Pós-Graduação (UFPI). Atualmente, coordena o Programa de Pós-Graduação em Letras da UFPI (mestrado e doutorado). E-mail: chicofilhoo@ufpi.edu.br
} 
History. The results of the analyzes showed us that the writers usually present, in the presentation section, besides the research theme, the objectives of the study, its questions and historical accounts. This research intends to contribute to the academic community, as it will be able to show future candidates for the Masters in History, which are the rhetorical steps most used in the composition of the research project, specifically in the "presentation of the research problem" section.

Keywords: Research project. Academic genres. Rhetorical organization.

\section{Introdução}

Na universidade, estamos rodeados por diversos gêneros acadêmicos. Dentre eles, destacamos o Projeto de pesquisa, que é utilizado de diversas formas no mundo acadêmico, seja como porta de acesso para financiamento de pesquisas seja como requisito para o ingresso em cursos de pós-graduação, em nível de mestrado ou de doutorado em boa parte das universidades brasileiras. Neste último caso, os candidatos participantes de seleções para ingressos em cursos de mestrado ou de doutorado necessitam recorrer ao projeto de pesquisa, pois, através deste, tentarão persuadir os membros da banca a aceitarem sua proposta de pesquisa.

O projeto de pesquisa é composto por algumas seções que podem ser denominadas de formas distintas dependendo da universidade ou do edital de seleção, os nomes podem mudar até mesmo de projeto para projeto. A seção que introduz o projeto e que busca esclarecer logo no início e dizer o que o pesquisador irá fazer, segundo Barros (2005), é a seção de "Delimitação temática", que pode ser denominado de formas distintas, como "Exposição do problema" ou "Apresentação da problemática de estudo". Trata-se da seção em que o pesquisador precisa definir qual o seu problema de pesquisa.

Na seção de delimitação temática, espera-se que o autor faça a introdução do seu projeto, além de definir e caracterizar a pesquisa que será realizada. Os editais de seleção para programas de pós-graduação das universidades brasileiras costumam definir quais os elementos que cada seção do projeto de pesquisa deve conter, ou seja, os editais procuram informar qual a expectativa da banca sobre cada seção do projeto, mas de acordo com Bazerman (2005), as pessoas nem sempre fazem as coisas da forma como são orientadas, às vezes as interpretam de formas diferentes ou buscam ampliar e realizar coisas diferentes das solicitadas. Nesta seção, também, é o local em que o pesquisador costuma esclarecer ao seu leitor - que irá avaliar e decidir se sua pesquisa merece ou não ser aprovada - qual é o objeto de 
sua investigação. Barros (2005) define esta seção como a que busca essencialmente esclarecer o que será pesquisado.

Apresentamos, nesta pesquisa, uma análise da seção de "apresentação da problemática de estudo" dos projetos de pesquisa submetidos e aprovados na seleção do mestrado em História do Brasil do Programa de Pós-Graduação em História do Brasil (PPGHB) da Universidade Federal do Piauí (UFPI) - Campus Ministro Petrônio Portella, nos anos de 2014 e 2015. Identificamos a organização retórica, categorizando os passos retóricos presentes na seção, com o intuito de saber como os mestrandos de História agem na hora de escrever a seção de "apresentação da problemática de estudo" em seus projetos de pesquisa.

\section{Gêneros textuais e organização retórica}

O conceito tradicional de gênero, para Swales (1990) não era claro nem satisfatório, porque o via apenas como uma fórmula textual, e, dessa forma, o ensino usando gêneros não era produtivo, por isso, Swales decidiu construir a sua própria concepção de gênero textual. Segundo Hemais e Biasi-Rodrigues (2005), o autor se baseou em quatro áreas de estudo para construir o seu conceito de gênero: os estudos do folclore - com a noção de que as formas são permanentes, mas sofrem mudanças em seu papel social, os estudos literários - com a sua não estabilidade do gênero, a linguística - com a noção de eventos comunicativos tipificados, e a retórica - que classifica os diversos tipos de discurso.

Baseado nessas quatro áreas de estudo, Swales (1990) percebeu que os gêneros possuem cinco características fundamentais: a ideia de classe, o propósito comunicativo, a prototipicidade, a lógica subjacente aos gêneros e a terminologia. Após se basear em áreas de estudo diferentes, e definir as características de gênero textual, Swales elabora sua própria noção de gênero:

Um gênero compreende uma classe de eventos comunicativos, cujos membros compartilham um conjunto de propósitos comunicativos. Esses propósitos são reconhecidos pelos membros mais experientes da comunidade discursiva de origem e assim, constituem a razão do gênero. Essa razão molda a estrutura esquemática do discurso e influencia e restringe as escolhas de conteúdo e estilo. [...] (SWALES, 1990, p. 58, apud LIMA DE OLIVEIRA e ALEXANDRE, 2020, p. 222) 
O conceito de gênero textual de Swales, então, o vê principalmente por seus propósitos comunicativos, ou seja, por suas finalidades de comunicação que são reconhecidas por membros de determinadas comunidades [discursivas]. A abordagem sociorretórica de gêneros textuais de Miller (1996), Swales (1990) e Bazerman (2005) percebe os gêneros como ação social, ou seja, os gêneros são as formas de agir na sociedade. Com esta definição de gênero como ação social, Miller (1996) entende que uma definição retórica de gênero, para ser apropriado, necessita estar centrada na ação que foi utilizada para a sua realização e não, apenas, na substância ou na forma do discurso, ou seja, Miller (1996) vê os gêneros não focando em sua estrutura ou forma, mas sim em como o gênero foi feito e quais as formas de ação que são desenvolvidas mediante ele.

Ao analisar a organização retórica de uma seção de algum gênero acadêmico, o pesquisador leva em consideração três conceitos fundamentais, e são eles: propósito comunicativo, movimentos e passos retóricos. Vamos conhecer estes conceitos. O propósito comunicativo "corresponde à função retórico-comunicativa desempenhada por um gênero em contextos sociais delimitados" (ALVES FILHO, 2018, p. 138), ou seja, o propósito de um gênero tem a ver com a função que ele realiza na sociedade que o utiliza. Swales considerava o propósito comunicativo como o principal elemento para a caracterização de um gênero. Depois, Swales foi modificando, aos poucos, a base de sua teoria, e atualmente prioriza o contexto, isto é, os participantes e os elementos da situação que geram os textos pertencentes a um gênero (BIASI-RODRIGUES, 2007).

Para Askehave e Swales (2005), apontar o propósito comunicativo de um gênero não é sempre uma tarefa rápida e fácil, pois o propósito pode não ser tão explícito e ainda, um mesmo texto pode apresentar mais de um propósito comunicativo, como uma transmissão de notícias, que pode ter os propósitos de moldar a opinião pública, orientar o comportamento das pessoas ou melhorar a imagem de seus patrocinadores.

O movimento retórico é conceituado por Alves Filho (2018, p. 138) como aquilo que "indica uma função retórico-comunicativa relativamente padronizada desempenhada por agrupamentos de sequências textuais usadas em um gênero de texto particular ou em uma de suas seções", então, um movimento retórico não é, necessariamente, explícito no texto de forma linguística, mas é postulado pelo analista a partir do agrupamento de passos retóricos semelhantes. Motta-Roth e Hendges 
(1998) definem os movimentos retóricos como blocos discursivos presentes nos exemplares das seções de um gênero, ou seja, os movimentos retóricos são formas discursivas que se materializam no texto por meio de passos retóricos. Usando uma metáfora, as autoras (2010) relacionam o movimento retórico com um movimento em um jogo de xadrez, cujo objetivo é convencer o leitor da importância do texto e persuadi-lo a seguir lendo até o fim.

Os passos retóricos são as sequências textuais com intenções comunicativas socialmente compartilhadas. Dessa forma, os passos são localizáveis no texto e são menos abstratos que os movimentos, pois são desempenhados por uma sequência textual particular, que precisa ser recorrente em uma seção de um gênero. (ALVES FILHO, 2018).

Os trabalhos de pesquisa que analisam a organização retórica de gêneros acadêmicos buscam analisar os movimentos e/ou passos retóricos que são recorrentes em determinadas seções destes gêneros. De acordo com o modelo CARS, elaborado por Swales, que mostra a descrição dos movimentos e seus respectivos passos retóricos dentro da introdução de artigos de pesquisa, as introduções analisadas possuem três movimentos retóricos e cada um dos movimentos possui pelo menos um passo retórico, Swales infere que alguns passos retóricos devam aparecer de forma opcional e que outros, em contrapartida, são obrigatórios.

O modelo CARS de Swales para a análise de gêneros acadêmicos está sendo utilizado em versões adaptadas por vários analistas de gêneros. Pesquisadores brasileiros como Jucá (2006), Silva (2015), Rio Lima (2015), Sousa (2017), Alves Filho (2018) e Lima de Oliveira e Alexandre (2020) têm realizado pesquisas proveitosas com adaptações do modelo de análise de Swales.

Em sua dissertação de mestrado, Jucá (2006) analisou a organização retórica da seção de justificativa de projetos de dissertação, se baseando nas concepções de análise de gêneros textuais propostas por Swales e descreveu a recorrência de algumas unidades retóricas (movimentos retóricos) como Estabelecer um território geral, Estabelecer um território específico e Justificar uma nova pesquisa, que são compostas por passos retóricos, ou como o autor prefere nomear: subunidades.

Lima de Oliveira e Alexandre (2020) analisaram a seção "Identificação do problema de pesquisa" de projetos de pesquisa de Linguística. Em sua pesquisa, os 
autores encontraram nove passos retóricos recorrentes e dentre eles, um não descrito em pesquisas anteriores consultadas - Levantando hipóteses.

\title{
20 projeto de pesquisa e a Identificação do problema de pesquisa
}

Um projeto de pesquisa é, segundo Motta-Roth e Hendges (2010, p. 55), um "planejamento do que vamos fazer para investigar um determinado problema". Já Barros (2005) define o projeto de pesquisa como uma proposta de realizar algo e afirma que é um roteiro que deve ser usado como instrumento de planejamento para a pesquisa que será desenvolvida. A definição de Motta-Roth e Hendges (2010) se complementa com a de Barros (2005), pois o projeto de pesquisa serve como instrumento de planejamento e, concomitantemente, se caracteriza como o próprio planejamento para a pesquisa que será realizada.

Quando um candidato a um curso de mestrado submete seu projeto de pesquisa a uma banca de seleção, há a expectativa de que o autor do projeto convença os membros da banca de que a pesquisa será relevante e de que o pesquisador possui conhecimentos teóricos e metodológicos sobre o tema. Por isso, os candidatos ao mestrado, na escrita do projeto de pesquisa, utilizam formas de persuasão, sejam estas explícitas ou implícitas:

\begin{abstract}
Os pré-projetos de pesquisa submetidos à seleção de pós-graduação também compartilham essa natureza geral persuasiva, nesse caso visando persuadir a banca examinadora de que a proposta atende ao edital e às linhas de pesquisa do programa e oferece indícios de que o seu autor possui mérito acadêmico para ingressar num curso de pós-graduação. (ALVES FILHO, 2018, p. 134)
\end{abstract}

Para Barros (2005), iniciar uma pesquisa é partir para uma viagem que, ao mesmo tempo, instiga e desafia, caracterizando-se como uma aventura em que o pesquisador precisa construir, a cada momento, o seu próprio caminho de pesquisa. O destino a ser alcançado não é "mera questão de apontar o dedo para um ponto no mapa" (BARROS, 2005, p. 9), já que o pesquisador precisa, entre outras coisas, delimitar o tema e definir qual problema será investigado.

Uma das seções que se faz presente em um projeto de pesquisa é a seção de "Identificação do problema de pesquisa", a qual também recebe outras 
denominações, como "Delimitação temática" ou "Apresentação da problemática de pesquisa". Existem dois tipos de introdução de projetos de pesquisa na área de História. Quando o projeto apresenta um capítulo especial para a "delimitação temática", a introdução será uma espécie de resumo de todo o projeto. Se não houver o capítulo de "delimitação temática", ou, "apresentação do problema de estudo", a introdução será o local em que o tema será apresentado e discutido (BARROS, 2005).

Existem três dimensões, as quais tornam a pesquisa viável, e que, para Barros (2005), devem aparecer de forma bem clara na seção de "apresentação da problemática de estudo": o recorte espacial, o recorte temporal e o problema. O autor preconiza que os recortes espacial e temporal, no projeto de pesquisa de História, devem ser bem precisos. Além disso, a terceira dimensão, isto é, o problema de pesquisa, "tem, geralmente, um sentido interrogativo" (BARROS, 2005, p. 40), mas o autor alerta que o problema de pesquisa não precisa estar escrito de forma interrogativa, apenas o seu sentido é que necessita desse caráter interrogativo.

$\mathrm{Na}$ visão deste historiador todas essas informações de recortes espacial e temporal, delimitação do tema e especificação do problema que o pesquisador pretende investigar ao longo de sua pesquisa devem estar inseridas de forma explícita na seção de apresentação do problema de pesquisa, pois dessa forma, o leitor poderá se situar e saber se a pesquisa que será realizada o interessa ou não.

\section{Metodologia}

O corpus desta investigação é formado por 15 projetos de pesquisa da área de História, submetidos e aprovados em seleções para o mestrado acadêmico em História do Brasil da Universidade Federal do Piauí - UFPI, nos anos de 2014 e 2015. Todos os projetos de pesquisa foram cedidos pelos mestrandos de História. Os nomes dos autores dos projetos - assim como os títulos dos projetos - foram ocultados para garantir anonimato aos pesquisadores. Foram criados códigos alfanuméricos para referir os projetos. A escolha de projetos aprovados se deveu ao fato de que sua aprovação na banca de seleção significa que a academia confere algum mérito acadêmico às propostas de pesquisa.

Inicialmente, lemos todos os 15 projetos de pesquisa selecionados integralmente a fim de tomarmos conhecimento da proposta global do candidato. Em seguida fizemos a leitura da seção de apresentação do problema de pesquisa 
(embora ela possa vir nomeada de outra forma). A análise textual buscou identificar os trechos dos textos indiciadores dos passos retóricos mais recorrentes.

Em leituras posteriores analisamos estes trechos em relação à proposta global do projeto. Para a nomeação de eventuais novos passos retóricos encontrados, usamos o mesmo tipo de anotação proposto por Swales (1990), através do recurso de verbos na forma do gerúndio (afirmando, reivindicando, prevendo). Fizemos a análise de acordo com o proposto por Alves Filho (2018), abandonando a noção de movimento retórico, analisando, dessa forma, apenas os passos retóricos recorrentes na seção do gênero, pois os movimentos retóricos são categorias postuladas pelos pesquisadores a partir da semelhança de certos passos retóricos, enquanto os passos são localizáveis no texto, através, geralmente, das pistas linguísticas.

Devido às diversas formas de realização do passo retórico $P 3$ - Relatando pesquisa prévia, analisamos como os mestrandos geralmente realizam esse passo retórico na Apresentação do problema de estudo de seus projetos de pesquisa. Dessa forma, procuramos descobrir qual o tipo de informação que os candidatos mais relatam através das pesquisas prévias, se são de caráter metodológico como a metodologia de uma pesquisa realizada previamente que pode ser replicada; ou de caráter teórico, como conceitos e questões teóricas ou, ainda, se os mestrandos recorrem às conclusões e resultados de pesquisas prévias como forma de prosseguir com o que vem sendo pesquisado em sua área de pesquisa.

Ainda sobre o P3, também analisamos as pistas linguísticas recorrentes em suas realizações, além de observar de onde as informações que são relatadas são retiradas, se são de artigos de pesquisa, livros, monografias, dissertações de mestrado ou teses de doutorado. Atentamo-nos em saber se os autores citam as pesquisas prévias de forma individual com comentários a respeito do conteúdo e/ou da relevância da obra, ou se eles citam as pesquisas de forma coletiva, fazendo um comentário geral do conteúdo e/ou relevância do conjunto das pesquisas prévias.

Nas análises do P6 - Indicando lacunas no conhecimento, por sua vez, observamos como os mestrandos indicam as lacunas na sua área de pesquisa, se eles afirmam que há ausência total de pesquisas sobre um determinado tópico, se afirmam que há algumas pesquisas, mas que não são suficientes ou, ainda, se afirmam que há pesquisas, mas que elas se opõem, ou seja, mostram descobertas conflitantes. 
Classificamos a recorrência dos passos retóricos em categorias. A primeira é alta recorrência, na qual se encontram os passos retóricos com número igual ou superior a nove ocorrências. Em baixa recorrência consideramos aqueles passos retóricos com número inferior a cinco ocorrências. Por fim, os passos retóricos que se encontram neste intervalo (entre os de alta recorrência e os de baixa recorrência) são considerados passos retóricos de média recorrência, podendo ser média alta - que se aproximam mais da alta recorrência; ou média baixa - quando ocorre o inverso.

\section{Resultados e discussão}

Nesta seção, apresentamos os passos retóricos mais recorrentes na seção apresentação do problema de pesquisa de projetos de pesquisa de História, descrevendo-os e exemplificando-os detalhadamente. Os dez passos retóricos mais usados pelos mestrandos na elaboração da seção Apresentação do problema de pesquisa são os apresentados no quadro abaixo:

\section{Quadro 1 - Nomenclatura e status dos passos retóricos}

\begin{tabular}{|l|l|l|}
\hline P & \multicolumn{1}{|c|}{ PASSO RETÓRICO objetivos da } & \multicolumn{1}{|c|}{ STATUS } \\
\hline P1 & $\begin{array}{l}\text { Apresentando escrito em pesquisas consultadas } \\
\text { pesquisa }\end{array}$ & $\begin{array}{l}\text { Não descrito em pesquisas } \\
\text { consultadas }\end{array}$ \\
\hline P2 & Apresentando relato histórico & Descrito em pesquisas consultadas \\
\hline P3 & Relatando pesquisa prévia & $\begin{array}{l}\text { Desquisas } \\
\text { da pesquisa }\end{array}$ \\
\hline P5 & $\begin{array}{l}\text { Justificando a escolha do tema e/ou } \\
\text { do recorte temporal }\end{array}$ & $\begin{array}{l}\text { Não } \\
\text { consultadas }\end{array}$ \\
\hline P6 & Indicando lacunas no conhecimento & Descrito em pesquisas consultadas \\
\hline P7 & Indicando aspectos metodológicos & Descrito em pesquisas consultadas \\
\hline P8 & $\begin{array}{l}\text { Justificando a relevância da } \\
\text { pesquisa }\end{array}$ & Descrito em pesquisas consultadas \\
\hline P9 & Justificado a escolha da fonte & Descrito em pesquisas consultadas \\
\hline P10 & Delimitando fonte da pesquisa & Descrito em pesquisas consultadas \\
\hline
\end{tabular}

Fonte: produzido pelos próprios pesquisadores. 
No gráfico a seguir, vemos os passos retóricos em ordem decrescente de recorrência. Dessa forma, o P1 - Apresentando objetivos da pesquisa; P2 Apresentando relato histórico; P3 - Relatando pesquisa prévia e P4 - Formulando questões norteadoras da pesquisa são os passos mais recorrentes, enquanto P9 Justificando a escolha da fonte e P10 - Delimitando fonte de pesquisa são os menos recorrentes nos projetos pertencentes ao nosso corpus de pesquisa.

\section{Gráfico 1 - Listagem de recorrência dos passos retóricos}

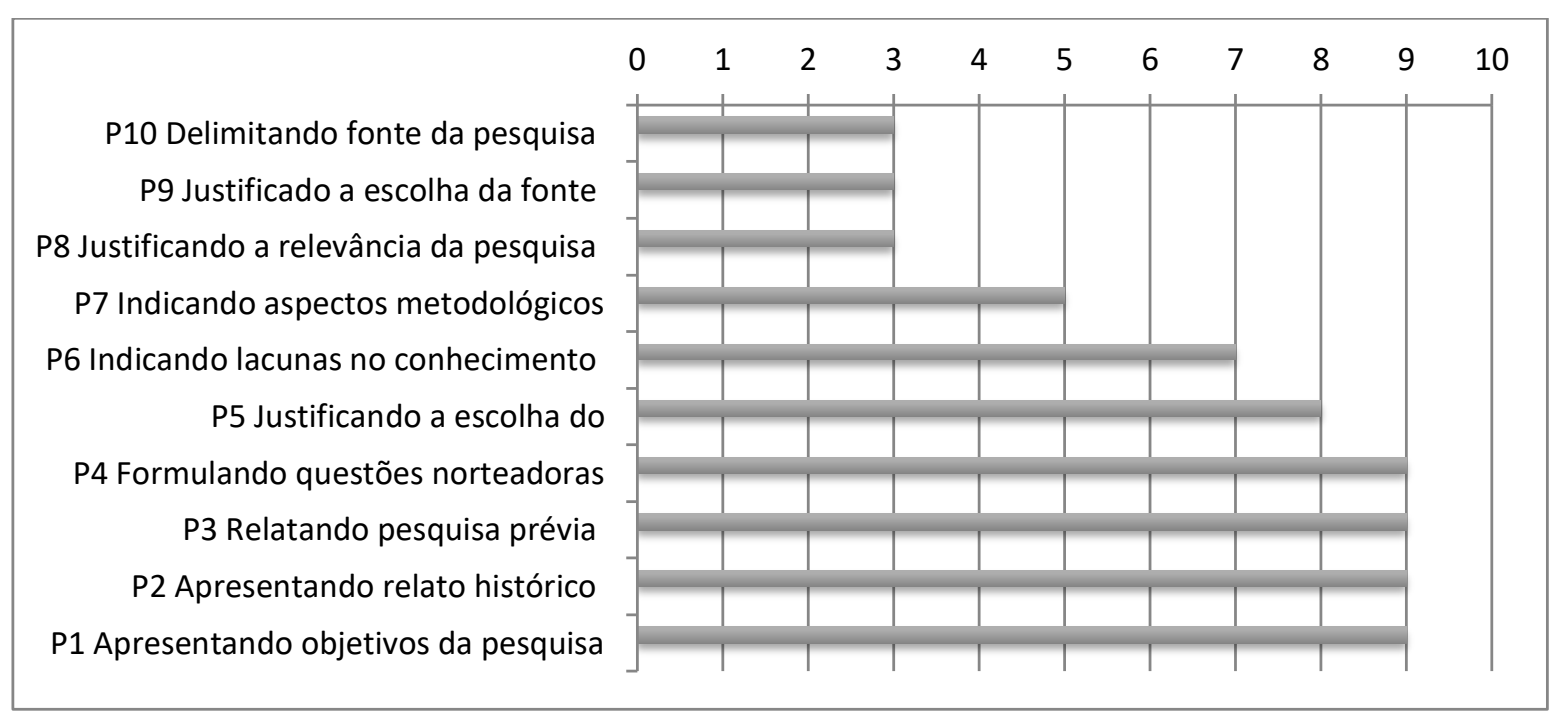

Fonte: produzido pelos próprios pesquisadores.

Os passos retóricos mais recorrentes possuem no máximo nove ocorrências. Considerando que o corpus é composto por quinze projetos de pesquisa, podemos perceber que nenhum dos dez passos retóricos recorrentes aparece em todos os projetos analisados, tampouco nenhum chega a dez ocorrências. Também podemos notar que não existem passos retóricos obrigatórios para a seção Identificação do problema de pesquisa, uma vez que não há nem um passo retórico encontrado em todos os projetos analisados.

Como observado em nossas análises e constatado em pesquisas anteriores, realizadas com projetos de outras áreas (ALVES FILHO, 2018; LIMA DE OLIVEIRA e ALEXANDRE, 2020), não existem dois projetos de pesquisa que possuam sua seção Identificação do problema de pesquisa com os mesmos passos retóricos organizados exatamente na mesma sequência, isto mostra que a seção é bastante instável, além de demonstrar a baixa convenção retórica de escritores iniciantes na pesquisa científica. No quadro abaixo, iremos observar a ocorrência dos passos retóricos e em quantos projetos um passo foi utilizado, além de vermos a sua recorrência. 


\section{Quadro 2 - Recorrência dos passos retóricos}

\begin{tabular}{|c|c|c|c|c|}
\hline $\mathbf{P}$ & Nome do passo & Ocorrências & $\begin{array}{l}\text { Quantidade } \quad \text { de } \\
\text { projetos }\end{array}$ & Recorrência \\
\hline P1 & $\begin{array}{l}\text { Apresentando objetivos } \\
\text { da pesquisa }\end{array}$ & 9 & $9 / 15$ & Alta \\
\hline $\mathrm{P} 2$ & $\begin{array}{l}\text { Apresentando relato } \\
\text { histórico }\end{array}$ & 9 & $9 / 15$ & Alta \\
\hline P3 & $\begin{array}{l}\text { Relatando pesquisa } \\
\text { prévia }\end{array}$ & 9 & $9 / 15$ & Alta \\
\hline $\mathrm{P} 4$ & $\begin{array}{l}\text { Formulando questões } \\
\text { norteadoras da pesquisa }\end{array}$ & 9 & $9 / 15$ & Alta \\
\hline P5 & $\begin{array}{l}\text { Justificando a escolha do } \\
\text { tema e/ou do recorte } \\
\text { temporal }\end{array}$ & 8 & $7 / 15$ & Média alta \\
\hline P6 & $\begin{array}{l}\text { Indicando lacunas no } \\
\text { conhecimento }\end{array}$ & 7 & $5 / 15$ & Média \\
\hline P7 & $\begin{array}{l}\text { Indicando aspectos } \\
\text { metodológicos }\end{array}$ & 5 & $5 / 15$ & Média baixa \\
\hline P8 & $\begin{array}{l}\text { Justificando a relevância } \\
\text { da pesquisa }\end{array}$ & 3 & $3 / 15$ & Baixa \\
\hline P9 & $\begin{array}{l}\text { Justificado a escolha da } \\
\text { fonte }\end{array}$ & 3 & $3 / 15$ & Baixa \\
\hline P10 & $\begin{array}{l}\text { Delimitando fonte da } \\
\text { pesquisa }\end{array}$ & 3 & $3 / 15$ & Baixa \\
\hline
\end{tabular}

Fonte: produzido pelos próprios pesquisadores.

Agora partimos para a descrição dos passos retóricos mais recorrentes (excluindo os que apresentaram baixa recorrência) usados pelos mestrandos de História na construção da seção Identificação do problema de pesquisa de seus projetos de pesquisa.

O passo retórico mais recorrente é o $P 1$ - Apresentando Objetivos da Pesquisa e ocorreu em nove projetos de pesquisa da amostra e tem como função apresentar um ou mais objetivos da pesquisa que será realizada. Mesmo que os projetos de pesquisa já possuam uma seção exclusiva para a apresentação dos objetivos geral e específicos, os escritores lançam mão deste passo na seção Apresentação do problema de estudo. 
Concordamos com Alves Filho (2018, p. 149) quando explica que os mestrandos apresentam os seus objetivos de pesquisa em mais de uma seção por um caráter persuasivo, pois "informações repetidas possuem um status de relevância acentuada". Dessa forma, este passo retórico é importante na seção inicial do projeto de pesquisa, principalmente, por ser importante esclarecer, logo no início, quais são os objetivos que o pesquisador pretende desenvolver com a pesquisa que será realizada.

(1) $\mathrm{H} 1405$.

Pretende-se, pois analisar neste trabalho a condição da mulher no século XIX e nas primeiras décadas do século $X X$ voltando o olhar para questões como casamento, educação e infância, bem como a condição da mulher escritora a partir da vida e obra de Amélia Beviláqua.

\section{(2) H1513.}

A pesquisa pretende analisar a violência de gênero, comumente tratada como violência doméstica, sofrida por mulheres parnaibanas, entre as décadas (1994/2015) na cidade de Parnaíba - PI.

As pistas linguísticas que auxiliaram na identificação deste passo retórico foram os verbos "analisar", "investigar", "observar”, "estudar”, "desenvolver” entre outros.

O P2 - Apresentando relato histórico ocorreu em nove projetos de pesquisa analisados. Tal passo ocorre quando o escritor relata acontecimentos históricos a respeito de algum fenômeno ou sobre o objeto de estudo em questão. Os verbos geralmente usados na construção deste passo retórico se encontram no pretérito, uma vez que relatam fatos já ocorridos em um determinado momento da História. Este passo retórico tem relação direta com os valores da cultura disciplinar da área de História, uma vez que possibilita um resgate histórico dos fatos mostrando como os acontecimentos presentes se relacionam com os do passado. Vejamos, pois, alguns exemplos:

(3) $\mathrm{H} 1502$

No Brasil um dos movimentos cinematográficos mais expressivos surgiu na década de cinquenta, denominado 
Cinema Novo e seu principal idealizador foi o jovem cineasta Glauber Rocha. Os cinemanovistas sempre exaltavam o lema "uma câmera na mão e uma ideia na cabeça", [...]. Com o tempo - Cinema Novo alia-se ao governo Militar brasileiro na década de 1970, talvez para fugir da censura ou possibilitar alcance maior do público, com isso fazendo surgir outro seguimento do cinema brasileiro chamado de Cinema Marginal, neste ultimo os filmes ficavam a margem dos circuitos exibidores do país.

No exemplo acima, podemos observar que o mestrando apresentou um relato histórico sobre o movimento cinematográfico "Cinema Novo", que surgiu na década de 50. O autor apresentou algumas características históricas do movimento, como a aliança com o governo militar na década de 1970. Logo abaixo, apresentamos outro exemplo do P2:
(4) $\mathbf{H 1 5 1 7}$
A prática do teatro em Teresina origina-se de sua fundação, em 1852, quando se tornou capital da província e abrigou artistas amadores da antiga sede, Oeiras. De 1852 a 1894 funcionaram teatros improvisados que acolhiam artistas locais e raros grupos profissionais que visitavam a cidade. Segundo Higino Cunha, o teatro era uma diversão estimada durante o século XIX, sendo impossível a concorrência por parte das demais diversões.

No exemplo de H1517, o autor apresenta um pequeno percurso histórico sobre os teatros em Teresina, apresentando datas e informações históricas relevantes para a pesquisa planejada sobre o seu objeto de investigação. As pistas linguísticas que nos ajudaram na identificação deste passo retórico foram os verbos no passado e as datas e séculos indicados pelos mestrandos nas realizações do passo Apresentando relato histórico.

O passo retórico $P 3$ - Relatando pesquisa prévia também ocorreu em nove projetos do corpus. O P3 é utilizado pelos mestrandos para expor pesquisas realizadas anteriormente que serviram de inspiração para a sua pesquisa, ou que possuam alguma afinidade, como o mesmo objeto de estudo, ou a mesma metodologia ou que se filiem à mesma corrente teórica.

Com a análise do corpus, observamos que em todas as realizações do P3 os mestrandos citam as obras de forma individual, ou seja, relatam apenas uma obra de pesquisa prévia e fazem comentários específicos sobre ela. Quanto aos conteúdos, predomina o relato de resultados e de conclusões das pesquisas consultadas. Os 
mestrandos relatam como pesquisas prévias, principalmente, suas monografias (3 ocorrências), livros (3) e artigos de pesquisa (2). Vamos ver alguns exemplos:

\section{(5) H1401}

No trabalho de conclusão de curso foi possível observar a partir, principalmente, de dados criminais da polícia e fontes da imprensa de Teresina, como alterações espaciais e nas maneiras dos indivíduos agirem em sociedade contribuíram para que perfis femininos pobres fossem catalogados como irregulares e anormais.

Na realização acima, o mestrando relatou, de forma individual, os resultados da pesquisa de sua monografia, ou seja, o candidato fez uma autocitação na hora de relatar pesquisas prévias. De forma semelhante, no exemplo a seguir, o autor apresentou os resultados de um artigo de pesquisa, e, na oportunidade, teceu comentários sobre a pesquisa.

\section{(6) $\mathrm{H} 1415$}

Monteiro (2004) foi um dos que iniciou esse processo de vontade de vida na obra de Torquato. Ao analisar seu trabalho anterior o pesquisador percebeu que também deu sua contribuição para a cristalização da imagem do poeta, todavia no trabalho que aqui citamos o mesmo dá "toques" para uma nova leitura de Torquato Neto:

Diferente do encontrado na Apresentação do problema de pesquisa de projetos de pesquisa de Linguística (Cf. LIMA DE OLIVEIRA e ALEXANDRE, 2020), aqui não encontramos realizações do passo retórico Relatando pesquisa prévia em que os mestrandos agrupassem várias pesquisas em comum, fazendo um comentário geral sobre $o$ assunto tratado em todos os trabalhos.

O P4 - Formulando questões norteadoras da pesquisa tem a função de apresentar as indagações, questionamentos ou questões norteadoras que deram inspiração para a realização da pesquisa pretendida. Os mestrandos, ao usarem este passo, podem fazer uma série de perguntas que planejam responder com a investigação científica. Porém, as indagações nem sempre aparecem em forma de 
pergunta, às vezes aparecem apenas com o tom interrogativo ou reflexivo, ou seja, as indagações podem ser explícitas ou implícitas.

\begin{abstract}
(7) $\mathbf{H 1 5 1 5}$
Para analisar a cidade de Parnaíba e as transformações econômicas e socioculturais das décadas de 1930 e 1940 partiuse de alguns questionamentos: - Como se deu a inserção da economia parnaibana aos mercados nacional e internacional? Quais os reflexos dessa inserção no espaço urbano de Parnaíba? Que influências estrangeiras passaram a vigorar na cidade de Parnaíba?
\end{abstract}

\title{
(8) $\mathrm{H} 1410$
}

A pesquisa surgiu de indagações como: a partir de que obras Teresina formou seu patrimônio cultural e educacional? Quais as influências das edificações na identidade e memória coletivas?

As pistas linguísticas que auxiliaram na identificação deste passo retórico são: "alguns questionamentos", "indagações", "questão norteadora”, "um problema emergiu" entre outras. Os mestrandos costumam apresentar vários questionamentos que pretendem responder com a pesquisa, como nos exemplos acima, ou apenas uma pergunta norteadora, como no exemplo abaixo:

\section{(9) $\mathrm{H} 1503$}

Portanto, diante do exposto, elaboramos a seguinte questão norteadora desta pesquisa: Quais as razões que possibilitaram o auge do futebol piauiense na década de 1970, e seu posterior declínio?

Como dito anteriormente, as perguntas podem ser formuladas diretamente, com o uso de interrogações como nos exemplos acima, ou de forma indireta, apenas com o tom interrogativo, sem o uso de interrogações, como veremos no exemplo a seguir.

\section{(10) H1513}

Uma análise se há por parte do Estado uma tentativa de ocultar a real dimensão da violência praticada contra as mulheres e sua possível falha no que diz respeito a proteção, prevenção e punição da violência de gênero na cidade. 
Na realização do $\mathrm{P} 4$ em H1513, o mestrando não fez vários questionamentos sobre assunto, apenas indicou qual sua inquietação que pretende responder com a pesquisa que será realizada, caso o projeto de pesquisa seja aprovado.

O P5 - Justificando a escolha do tema e/ou do recorte temporal consiste em apresentar informações que sirvam como justificativa para a escolha do seu tema de pesquisa ou do recorte temporal que será feito na pesquisa que pretende desenvolver. Este passo retórico também possui uma relação intrínseca com a cultura disciplinar de História, que está preocupada com a questão temporal de suas investigações. $\mathrm{O}$ P5 possui oito (8) ocorrências em sete (7) projetos de pesquisa. Vejamos alguns exemplos:
(11) $\mathbf{H 1 4 1 0}$
O recorte temporal envolve os anos de 1965 a 1985, período em que a cidade recebia as primeiras influências do movimento moderno na arquitetura e estava em processo de desenvolvimento econômico e cultural.

\section{(12) $\mathbf{H 1 5 0 4}$}

A escolha do recorte temporal entre 1920 e 1970 se dá por ele abranger desde a entrada mais maciça dos imigrantes à sua fixação, incluindo o auge e o declínio de suas atividades comerciais. O que me permitiria desenvolver um estudo amplo que contemplasse meu objeto de uma forma geral.

As pistas linguísticas que deram auxílio na identificação deste passo retórico foram: "a escolha do recorte temporal", "recorte temporal", "opção pelo tema", "importância do recorte temporal" entre outros. Este passo retórico é esperado por Barros (2005), que afirma que é importante que, na seção de Delimitação temática, ou no nosso caso, de Apresentação do problema de pesquisa, o mestrando deixe claro qual o recorte temporal de sua pesquisa.

A investigação científica é feita buscando preencher lacunas no conhecimento de uma determinada área de pesquisa. O passo retórico P6 - Indicando lacunas no conhecimento é usado para mostrar as lacunas que o mestrando pretende preencher 
na área de pesquisa na qual a investigação será desenvolvida. Tal passo teve sete ocorrências em cinco projetos de pesquisa pertencentes ao corpus.

Aqui observamos como os mestrandos indicam as lacunas na sua área de pesquisa, se afirmam que há ausência total de pesquisas, insuficiência de pesquisas ou pesquisas com resultados conflitantes. Em três das realizações do P6, os mestrandos afirmaram que há pesquisas insuficientes sobre o seu tópico de pesquisa; dois mestrandos destacaram ausência total de pesquisas sobre uma determinada característica. Contudo, nenhuma das realizações deste passo fez o contraste entre pesquisas com resultados conflitantes. Veremos agora alguns exemplos.

(13) H1415

O trabalho de Andrade (2002) é importante no sentido de comentar os imprevisíveis significados da obra poética de Torquato Neto, sua forma, etc., mas pouco contribui para a discussão que levantamos. Não estamos aqui dizendo que isso não foi feito, estamos afirmando que não foi feito de maneira satisfatória.

No exemplo acima, podemos observar que o pesquisador relata que existe uma pesquisa sobre a obra poética de Torquato Neto, mas afirma que ela pouco contribui. Dessa forma, o autor avalia a pesquisa prévia como negativa, pois não contribui para a sua investigação. A seguir, apresentamos outra realização do P6.

\section{(14) H1410}

Ao constatar que os estudos na área de arquitetura moderna educacional estão centrados em abordagens técnicas ou ambientais percebeu-se a ausência e necessidade da abordagem patrimonial urbana.

No exemplo de H1410, o mestrando afirma que existem estudos na área moderna educacional, porém eles estão centrados em abordagens técnicas ou ambientais. Dessa forma, ele relata que há ausência total de pesquisas da abordagem patrimonial urbana, uma vez que os estudos se concentram em outros aspectos.

O passo $P 7$ - Indicando aspectos metodológicos ocorreu em cinco projetos de pesquisa e tem como função apresentar aspectos metodológicos da pesquisa proposta. Os projetos de pesquisa possuem uma seção destinada à apresentação da 
metodologia de pesquisa, mas alguns retores antecipam algumas observações metodológicas na seção inicial do projeto, isto é, na seção de apresentação do problema de pesquisa.

Os candidatos ao mestrado, ao usarem o passo retórico responsável por indicar aspectos metodológicos da pesquisa, escrevem no pretérito (2 ocorrências) e no futuro (2 ocorrências), houve uma ocorrência também no gerúndio. Vejamos, pois, alguns exemplos deste passo retórico em projetos de pesquisa de História.

\begin{abstract}
(15) H1401
Nessa perspectiva abordamos os sujeitos múltiplos que agiram na divulgação de padrões sobre o feminino, as relações de poder estabelecidas entre o aparelho jurídico-policial e a sociedade e o tecido entre os próprios indivíduos, e os perfis de "criminosas" que emergiam nesse percurso sócio- jurídico.
\end{abstract}

(16) H1414

Para isso faremos um dialogo entre a memória dessas pessoas e a documentação existente, incluindo o registro de atas que Federação mantinha no cartór io e matérias jornalísticas publicadas sobre a Umbanda no Estado.

As pistas linguísticas que ajudaram na identificação do passo retórico foram: "faremos", "abordamos", "foram realizadas" entre outras. O projeto de pesquisa é um gênero produzido antes de uma pesquisa científica, dessa forma, espera-se que a pesquisa seja feita após o projeto de pesquisa. Nas realizações do passo retórico acima, observamos que alguns pesquisadores utilizaram o tempo verbal no passado, como se a pesquisa já tivesse sido realizada.

\title{
Considerações finais
}

Nesta pesquisa, objetivamos analisar os passos retóricos recorrentes na seção Apresentação do problema de pesquisa de projetos de pesquisa de História. Com a análise dos passos retóricos mais usados pelos candidatos ao mestrado em História, pudemos descobrir como os mestrandos de História agem retoricamente ao apresentar o seu problema de pesquisa. Descobrimos dez passos retóricos relativamente recorrentes: Apresentando objetivos da pesquisa; Apresentando relato histórico; Relatando pesquisa prévia; Formulando questões norteadoras da pesquisa; Justificando a escolha do tema e/ou do recorte temporal; Indicando lacunas no 
conhecimento; Indicando aspectos metodológicos; Justificando a relevância da pesquisa; Justificado a escolha da fonte e Delimitando fonte da pesquisa.

Da mesma forma como em pesquisas anteriores (ALVES FILHO, 2018; LIMA DE OLIVEIRA e ALEXANDRE, 2020) não encontramos nenhum passo retórico presente em todos os projetos de pesquisa de História, o que nos confirma que não existem passos obrigatórios para a seção do gênero. Também não houve dois projetos que possuíssem os mesmos passos retóricos sequenciados exatamente na mesma ordem, isso demonstra a baixa convenção retórica esperada para pesquisadores iniciantes.

Dentre os passos retóricos recorrentes, encontramos dois que não foram descritos em pesquisas anteriores consultadas: Apresentando relato histórico e Justificando a escolha do tema e/ou do recorte temporal. Nossa pesquisa possui limitações como o fato de possuir um corpus reduzido, composto por quinze projetos de pesquisa. Além disso, não pudemos investigar o contexto de produção dos préprojetos, através, principalmente, de conversas e entrevistas com os produtores dos projetos de pesquisa e de seus respectivos professores orientadores.

Por fim, novas investigações poderão ser feitas com um corpus composto por mais projetos de pesquisa e com análises dos passos retóricos em outras seções do gênero. Esperamos, por outro lado, que esta pesquisa possa contribuir para a comunidade acadêmica da área de História, proporcionando um maior entendimento sobre como a seção Apresentação do problema de pesquisa dos projetos de História é produzida pelos candidatos ao mestrado desta área, pois assim, os futuros candidatos ao mestrado poderão saber o que é esperado na seção e o que geralmente é feito em projetos que foram aprovados pela banca de seleção.

\section{REFERÊNCIAS}

ALVES FILHO, Francisco. Gêneros jornalísticos: notícias e cartas de leitor no ensino fundamental. São Paulo: Cortez, 2011.

ALVES FILHO, Francisco. Como mestrandos agem retoricamente quando precisam justificar suas pesquisas. Revista Brasileira de Linguística Aplicada, v. 18, n. 1, 2018.

ASKEHAVE, Inger; SWALES, John M. Identificação de gênero e propósito comunicativo: um problema e uma possível solução. In: BEZERRA, Benedito Gomes; BIASI-RODRIGUES, Bernardete; CAVALCANTE, Mônica Magalhães (orgs.). Gêneros e sequências textuais. Recife: Edupe, 2009. p. 221-247. 
BARROS, José D’Assunção. O Projeto de Pesquisa em História. Petrópolis: Editora Vozes, 2005.

BAZERMAN, Charles. Gêneros textuais, tipificação e interação. São Paulo: Cortez, 2005.

Retórica da ação letrada. São Paulo: Parábola Editorial, 2015.

BIASI-RODRIGUES, B. O papel do propósito comunicativo na análise de gêneros: diferentes versões. In: SIMPOSIO INTERNACIONAL DE ESTUDOS DE GÊNEROS TEXTUAIS (SIGET), 4., Tubarão, SC. Anais... Tubarão/SC: UNISUL, 2007. p. 729742.

LIMA DE OLIVEIRA, Jancen Sérgio; ALEXANDRE, Leila Rachel Barbosa. Como mestrandos de linguística agem retoricamente quando elaboram sua identificação do problema de pesquisa. LETRAS EM REVISTA, [S.I.], v. 11, n. 01, jun. 2020. ISSN 2318-1788. Disponível em: <https://ojs.uespi.br/index.php/ler/article/view/235>.

LIMA DE OLIVEIRA, Jancen Sérgio. Movimentos retóricos da seção Apresentação do problema de estudo de projetos de pesquisa da área de História. Teresina: ICV, 2019. $15 \mathrm{p}$.

MARCUSCHI, Luiz Antônio. Produção textual, análise de gêneros e compreensão. São Paulo: Parábola Editorial, 2008.

MOTTA-ROTH, Désirée; HENDGES, G.R. Produção textual na universidade. São Paulo: Parábola Editorial, 2010. Série Estratégias de ensino.

. Uma análise transdisciplinar do gênero abstract. Intercâmbio, v. VII, 1998.

HEMAIS, Bárbara; BIASI-RODRIGUES, Bernardete. A proposta sociorretórica de John M. Swales para o estudo de gêneros textuais. In: MEURER, JOSÉ LUIZ; BONINI, ADAIR; MOTTA-ROTH, DESIRÉE. (Org.). Gêneros: teorias, métodos, debates. Rio de Janeiro: Parábola Editorial, 2005, p. 108-129.

MOTTA-ROTH, Désirée; HENDGES, G.R. Produção textual na universidade. São Paulo: Parábola Editorial, 2010. Série Estratégias de ensino.

RIO LIMA, Carolina Aurea Cunha. Movimentos retóricos da seção de fundamentação teórica de projetos de pesquisa da subárea de Linguística. Teresina: PIBIC, 2015.

SILVA, Camila Rayssa Barbosa da. Movimentos retóricos da seção de justificativa de pré-projetos de pesquisa da subárea de Linguística. Teresina: PIBIC, 2015.

SOUSA, Leonardo da Cunha. Recursos léxico-gramaticais recorrentes na seção Justificativa em pré-projeto de pesquisa das subáreas de Linguística. Teresina: PIBIC, 2017.

SWALES, John M. Genre analysis: english in academic and researching settings. Cambridge: Cambridge University Press, 1990. 